\title{
Social Habits and Other Risk Factors that Cause Tooth Loss: An Associative Study Conducted in Taiz Governorate, Yemen
}

\author{
Nashwan A Noman ${ }^{1}$, Adel A Aladimi ${ }^{2}$, Baleegh A Alkadasi ${ }^{3,4}$, Mohammed A Alraawi ${ }^{5}$, Gassan M Al-Iryani ${ }^{6}$, Fawzia I Shaabi ${ }^{7}$, \\ Asaad Khalid ${ }^{8}$, Mohammed M Al Moaleem ${ }^{9,10}$
}

\begin{abstract}
Aims: To investigate the relationship between tooth loss, age, gender, and its correlation with several local habits that affect oral health, especially the khat, and Shammah use.

Materials and methods: The current study included 580 participants. They were divided into five age groups15-24, 25-34, 35-44, 45-54, and 55-64-years-old. Clinical and radiographic examinations were done for each subject. Reasons for teeth loss, age, gender, khat chewing, Shammah use, smoking, and use of oral hygiene aids were recorded. The data were statically analyzed using Chi-square tests of the statistical package for social sciences (SPSS) program. The $p$ value $<0.05$ were considered statistically significant.

Results: Caries was the most cause of tooth loss in the young age groups 15-34 years-old and was significantly more common compared to the older groups $(p<0.001)$. The periodontal diseases increased with age and progressively became the main cause of tooth loss of $100 \%$ in the 55-64 years-old group. Orthodontic reasons for tooth extractions were limited to the young age group 15-24 years old. Third molars were the highest extracted teeth in the maxillary arch, while the first molars were the highest in the mandibular arch. Anterior teeth were the lowest extracted teeth ranging from $9 ; 1.6 \%$ in maxillary teeth and $9-29 ; 1.6-5 \%$ in the mandibular teeth.
\end{abstract}

Conclusion: This study highlights the importance of local habitual use of khat $52.9 \%$ and Shammah $8.1 \%$ besides smoking in tooth loss. Caries was the main cause of tooth loss in the young age groups, followed by the periodontal disease in the older age. Molars were frequently extracted followed by maxillary first premolars.

Clinical significance: Limited number of epidemiological surveys were carried out in Taiz Governorate to investigate the reasons of tooth loss and its relationship with social habits like Khat chewing, Shammah use, smoking, using of Miswake and toothbrush. The results of this study will guide us to develop a preventive program which may minimize tooth loss and its adverse effects.

Keywords: Dental caries, Khat, Meswake, Periodontal disease, Shammah, Smoking, Teeth extraction.

The Journal of Contemporary Dental Practice (2019): 10.5005/jp-journals-10024-2534

\section{INTRODUCTION}

oss of teeth is considered a major public health problem Lworldwide. Tooth extraction is the last option in dental treatment. A decrease in the number of teeth might result in poor dietary habits and deterioration of the quality of life. ${ }^{1}$ The number of extracted teeth can serve as an indicator of socioeconomic status, level of the oral hygiene and, treatment provided by the governmental services. ${ }^{2}$ Extraction of permanent teeth might be performed for several reasons, including dental caries, periodontal disease (PD), orthodontic treatments, periapical pathosis (PA), failed root canal treatment (RCT), trauma, and iatrogenic causes. ${ }^{3-25}$

A large number of cross-sectional studies had investigated the reasons for tooth loss in various countries. Dental caries was the main cause of tooth loss among the young age groups. ${ }^{3-9}$ while other researchers concluded that dental caries is the most common reason among elder age groups. ${ }^{4-10}$ Many studies have indicated that both caries and periodontal diseases are the common causes of teeth loss, ${ }^{15-23}$ but only a few studies have reported a greater proportion of teeth extractions due to periodontal disease. ${ }^{3,24-25}$

Even though, orthodontic reasons account for a small proportion, i.e., $<10 \%$ of tooth losses, $, 5-7,12,18-20,22$ some studies have reported a higher percentage $\mathrm{e}^{3,6,15,23}$ and sometimes reached more than the periodontal disease percentage. ${ }^{4}$ Few studies have registered parameters of teeth loss, such as trauma ${ }^{5,10,16,19-20,23,25}$ and root canal failures, ${ }^{5,9,10,18}$ while only one study has investigated the iatrogenic causes of tooth loss. ${ }^{7}$

\begin{abstract}
${ }^{1-3,9}$ Department of Dentistry, Faculty of Medicine, Taiz University, Taiz, Yemen

${ }^{4}$ Department of Periodontics, Faculty of Dentistry, IBB University, IBB, Yemen ${ }^{5}$ Department of Orthodontics, College of Dentistry, University of Mustafa Kemal, Antakya, Turkey

${ }^{6,7,10}$ College of Dentistry, Jazan University, Jazan, Kingdom of Saudi Arabia ${ }^{8}$ Substance Abuse Research Center, Jazan University, Jazan, Kingdom of Saudi Arabia
\end{abstract}

Corresponding Author: Mohammed M Al Moaleem, College of Dentistry, Jazan University, Jazan, Kingdom of Saudi Arabia, Phone: 00966-550599553, e-mail: drmoaleem2014@gmail.com

How to cite this article: Noman NA, Aladimi AA, Alkadasi BA, Alraawi MA, Al-Iryani GM, Shaabi FI, Khalid A, Al Moaleem MM. Social Habits and Other Risk Factors that Cause Tooth Loss: An Associative Study Conducted in Taiz Governorate, Yemen. J Contemp Dent Pract 2019;20(4):428-433.

Source of support: Nil

Conflict of interest: None

Khat and smokeless tobacco (Shammah) are prevalent habits in Yemen and neighboring areas. There are insufficient studies highlighting the potential association between these habits with teeth loss in Yemen, although it has been studied elsewhere. ${ }^{16,26-27}$ The effect of Khat and Shammah, ${ }^{28-30}$ smoking, ${ }^{7}$ and some other risk factors, such as oral hygiene measurements (using Miswake and teeth brushing) have been investigated earlier. ${ }^{7,11,31-33}$

Therefore, due to the insufficient studies on this topic in Yemen and particularly in Taiz Governorate and the need for such studies

(c) The Author(s). 2019 Open Access This article is distributed under the terms of the Creative Commons Attribution 4.0 International License (https://creativecommons. org/licenses/by-nc/4.0/), which permits unrestricted use, distribution, and non-commercial reproduction in any medium, provided you give appropriate credit to the original author(s) and the source, provide a link to the Creative Commons license, and indicate if changes were made. The Creative Commons Public Domain Dedication waiver (http://creativecommons.org/publicdomain/zero/1.0/) applies to the data made available in this article, unless otherwise stated. 
to minimize future extractions and for developing prevention plans. This study was conducted aiming to investigate the reasons of loss of permanent teeth and the correlation of tooth mortality with several factors that can affect oral health, as well as its association with age, gender, and location in the arch.

\section{Materials and methods}

The current retrospective cross-sectional study was conducted among subjects attending dental treatment in Taiz, Yemen. The data were collected at Al-Saeed University clinics, Al-Hikmah University clinics, Al-Thawrah Hospital, and at several other private clinics in war-free areas of Taiz, Yemen. This study was conducted in full accordance with the World Medical Association Declaration of Helsinki, and ethical approval was obtained from the Ethics Committee of the Director of the Health Affairs in Taiz region.

The data collection was carried out during the period from December 2017 to February 2018. A total of 580 participants (278; males and 302; females) were enrolled in this study. Patients of both genders, above the age of 15 years and without systemic diseases, were included in the study. The selected subjects were divided into five age groups, 15-24, 25-34, 35-44, 45-54, and 55-64-years-old. The participants were selected through nonprobability convenience sampling. Data were collected by dentists who were provided a short period of training using a predesigned questionnaire. The clinical intraoral and radiographic examinations of subjects were performed using dental diagnostic kits. All files and patients records were evaluated after written consent had been obtained from each patient.

The questionnaire was a single page and designed to be as simple as possible. The examinations were done to register the causes of tooth loss in relation to gender, age, and area of missing teeth. Other variables recorded included khat chewing, Shammah use, smoking, the use of miswake and tooth brushing. The questions addressing the sites of khat chewing and shammah use were also recorded. Data concerning the missing teeth causes were classified and recorded using the criteria mentioned by Cahen et al. $^{34}$ and Ainamo et al. ${ }^{35}$ with some slight modifications. The criteria were caries (whenever the primary cause of extraction is associated with caries, root remnant, fracture of tooth weakened by caries or previous treatments); periodontal disease (when the reason for extraction is pronounced periodontal breakdown, a loose suppurating tooth); failures of root canal treatments (when symptoms resist healing); trauma (when a non-carious associated trauma to the tooth is the reason for its removal); orthodontic treatments (whenever a tooth is removed under the request from the orthodontist); iatrogenic (due to incorrect performance or treatments done in dental clinics). Periapical diseases or lesions (PA) and other reasons for extractions were also recorded.

Data were collected and summarized as frequencies and percentages, then analyzed descriptively using SPSS software (version 20.1 SPSS, Chicago, Illinois, USA). A comparison and association with different variables were done using the Chi-square test. $P$ values $<0.05$ were considered significant.

\section{Results}

The current study included 580 subjects, $278 ; 47.9 \%$ males and $302 ; 52.1 \%$ females. Most of the subjects $226 ; 40.5 \%$ were in the $15-24$-age group, followed by $221 ; 38.1 \%$ subjects among the $25-34-$ age group. The age groups $35-44$ and $45-54$-years were $84 ; 14.5 \%$ and $39 ; 6.7 \%$, while $10 ; 1.2 \%$ subjects were among the smallest 55-64-age group. The frequency and percentage of khat chewers among all participants were $307 ; 52.9 \%$ subjects, and $240 ; 41.4 \%$ subjects of which patients chewing khat daily. The Shammah users were $47 ; 8.1 \%$ of total number of subjects, while $367 ; 63.3 \%$ were smokers. The number of subjects using toothbrush and Meswake were $256 ; 44.1 \%$, and $61,10.5 \%$, respectively. The use of the left side of the oral cavity in khat chewing and Shammah was higher than the right side $223 ; 38.4 \%$ and $32 ; 5.5 \%$, respectively (Table 1).

Table 2 shows the association between age groups and the causes of tooth loss. Dental caries was the most common cause of tooth loss among the young age groups 25 -34-years $121 ; 65.4 \%$, and 15-24-years $105 ; 43.0 \%$, and the difference had a significant value $p<0.05$. In the current study, the rate of periodontal disease was low in the young age groups $15-24$-years; $4.1 \%$ and $25-34$-years;

Table 1: Descriptive of subjects in relation to gender, social habits, and risk factors of tooth loss

\begin{tabular}{|c|c|c|c|c|c|c|c|c|c|c|c|c|c|c|c|c|}
\hline \multicolumn{17}{|c|}{ Gender, social habit, and risk factors } \\
\hline \multirow[b]{2}{*}{ Parameter } & \multicolumn{2}{|c|}{ Gender } & \multicolumn{2}{|c|}{ Khat chewing } & \multicolumn{2}{|c|}{ Khat site } & \multicolumn{2}{|c|}{ Shammah } & \multicolumn{2}{|c|}{ Shammah site } & \multicolumn{2}{|c|}{ Toothbrush } & \multicolumn{2}{|c|}{ Miswake } & \multicolumn{2}{|c|}{ Smoking } \\
\hline & Male & Female & Yes & No & Left & Right & Yes & No & Left & Right & Yes & No & Yes & No & Yes & No \\
\hline Number & 278 & 302 & 307 & 273 & 223 & 84 & 47 & 533 & 32 & 15 & 256 & 324 & 61 & 519 & 367 & 213 \\
\hline Percentage & 47.9 & 52.1 & 52.9 & 47.1 & 38.4 & 14.5 & 8.1 & 91.9 & 5.5 & 2.6 & 44.1 & 55.9 & 10.5 & 89.5 & 63.3 & 36.7 \\
\hline
\end{tabular}

Table 2: Association between different age groups and cause of tooth loss

\begin{tabular}{|c|c|c|c|c|c|c|}
\hline Factor/age group & $15-24$ & $25-34$ & $35-44$ & $45-54$ & $55-64$ & $p$ value \\
\hline Caries & 105 (43.0\%) & $121(65.4 \%)$ & $22(3.8 \%)$ & $10(21.3 \%)$ & $0(0.0 \%)$ & $0.000 *$ \\
\hline PD & $10(4.1 \%)$ & 55 (29.3\%) & $44(7.6 \%)$ & 29 (61.7\%) & $10(100 \%)$ & $0.000^{*}$ \\
\hline Orthodontic & $65(26.6 \%)$ & $0(0.0 \%)$ & $9(1.6 \%)$ & $0(0.0 \%)$ & $0(0.0 \%)$ & $0.000 *$ \\
\hline latrogenic & $10(4.1 \%)$ & $9(4.9 \%)$ & $0(0.0 \%)$ & $0(0.0 \%)$ & $0(0.0 \%)$ & 0.100 \\
\hline Failure RCT & $18(7.4 \%)$ & $9(4.9 \%)$ & $0(0.0 \%)$ & $0(0.0 \%)$ & $0(0.0 \%)$ & 0.022 \\
\hline Trauma & $9(3.7 \%)$ & $9(4.9 \%)$ & $0(0.0 \%)$ & $0(0.0 \%)$ & $0(0.0 \%)$ & 0.135 \\
\hline PA lesion & $9(3.7 \%)$ & $9(4.9 \%)$ & $0(0.0 \%)$ & $0(0.0 \%)$ & $0(0.0 \%)$ & 0.135 \\
\hline I do not know & $0(0.0 \%)$ & $9(4.9 \%)$ & $9(1.6 \%)$ & $0(0.0 \%)$ & $0(0.0 \%)$ & $0.000 *$ \\
\hline Total & $226(40.5 \%)$ & $221(38.1)$ & $84(145 \%)$ & $39(6.7)$ & $10(1.2 \%)$ & \\
\hline
\end{tabular}

*Significant PD (periodontal diseases); Orth, Orthodontic; PA, Periapical; RCT, Root canal treatment 
Social habits and risk factors that cause tooth loss in Taiz, Yemen

$29.3 \%$, increased in the middle age group's $35-44$ years; $51.1 \%$ and 45-54 years; $61.7 \%$, and reached $100 \%$ among $55-64$-year-olds Related to gender, the frequency and percentage of tooth loss in the female subjects were more due to dental caries and periodontal diseases $191 ; 63.2 \%$ and $57 ; 18.9 \%$, while in males the periodontal disease was the main cause $95 ; 34.2 \%, p<0.001$. The other factors such as iatrogenic, failure RCT, trauma reasons, and unknown were non-significant among gender (Table 3).

The association between khat chewing and caries was not significant due to the equal percentage among subjects, but we did detect an association between Shammah use and caries $p<0.001$. The rate of periodontal disease was $40.1 \%$ and $80.9 \%$ among khat chewers and Shammah users respectively $p<0.001$. The other parameters of tooth extraction cause, such as iatrogenic cause and failure of RCT were significant among khat chewers $p$ value 0.019 and 0.029 , respectively. But the same causes were nonsignificant among subjects of Shammah user $p$ value 0.088 and 0.097 , respectively. Trauma and unknown causes were significant among Khat and Shammah user $p<0.001$. The PA lesion cause was significant among khat chewers $p<0.001$, but not significant among Shammah user with $p$ value 0.213 (Table 4).

Regarding the association between dental caries and brushing of teeth and smoking, the frequency and percentages were not significant. However, we did detect an association between
Meswake use and dental caries $p<0.001$. Among subjects with periodontal disease, it was significant among groups using toothbrushes $p<0.001$, but not significant among Meswake or smoking subjects. The orthodontic reasons for teeth extractions were very significant among the risk factors parameters $p<0.001$ for khat chewing, Shammah user, brushing and Meswake user and smokers patients (Table 4).

Graphs 1 and 2 show that the maxillary third molar was the most frequently extracted tooth in maxillary arch right, 83; $14.3 \%$ and left, $72 ; 12.4 \%$. The first molar was the highest in the

Table 3: Association between gender and cause of tooth loss

\begin{tabular}{llll}
\hline Factor/gender & Male & Female & p value \\
\hline Caries & $74(26.6 \%)$ & $191(63.2 \%)$ & $0.000^{*}$ \\
PD & $95(34.2 \%)$ & $57(18.9 \%)$ & $0.000^{*}$ \\
Orthodontic & $18(6.5 \%)$ & $47(15.6 \%)$ & $0.000^{*}$ \\
latrogenic & $18(6.5 \%)$ & $10(3.3 \%)$ & 0.057 \\
Failure RCT & $9(3.2 \%)$ & $18(6.0 \%)$ & 0.086 \\
Trauma & $9(3.2 \%)$ & $9(3.0 \%)$ & 0.532 \\
PA lesion & $0(0.0 \%)$ & $18(6.0 \%)$ & $0.000^{*}$ \\
I do not know & $0(0.0 \%)$ & $18(6.0 \%)$ & 0.135 \\
\hline
\end{tabular}

Table 4: Association between social habits, risk factors, and causes of tooth loss

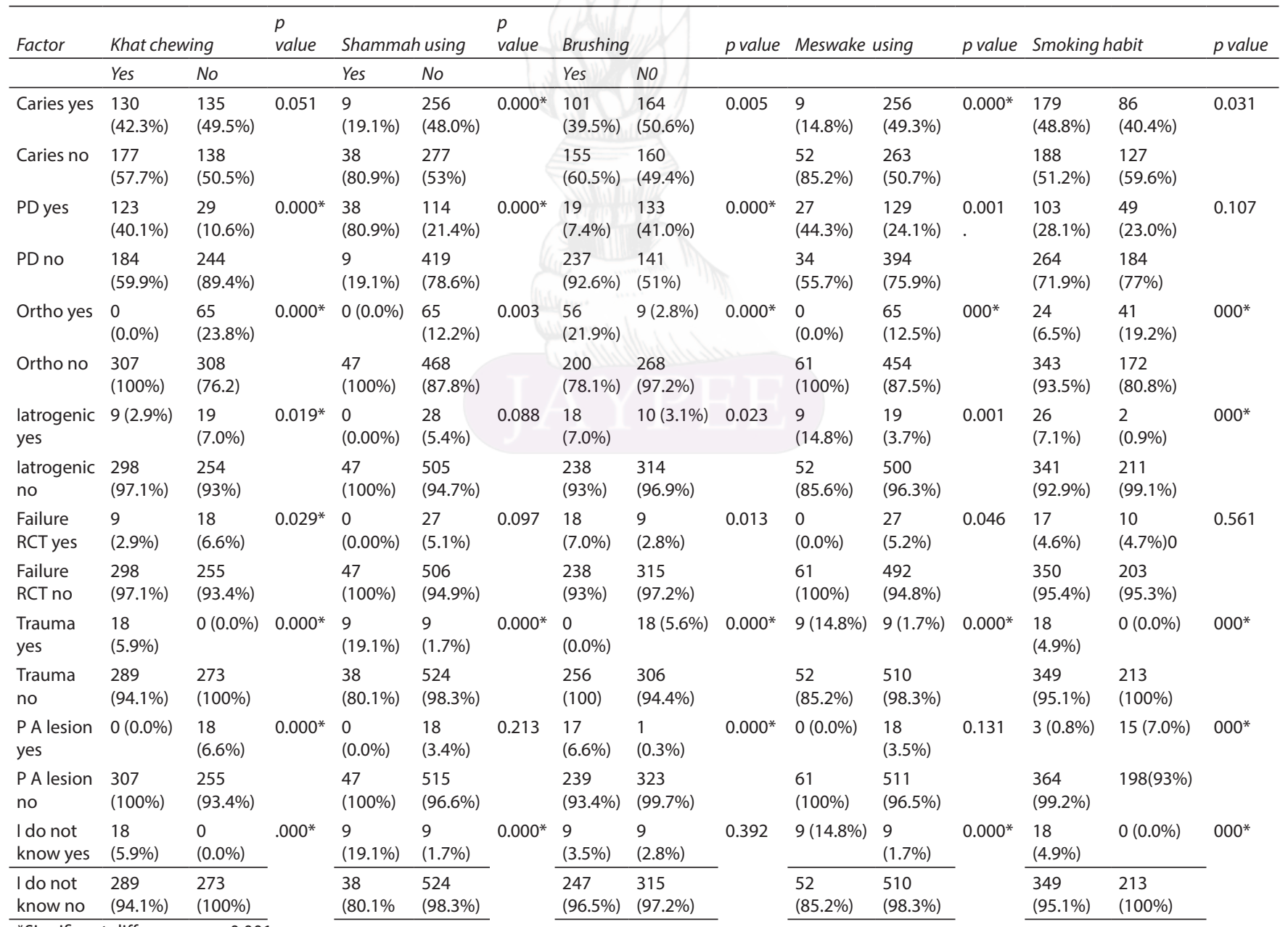

*Significant differences $p<0.001$.

Extractions for orthodontic reasons were mainly in the 15-24-year-old group. The other parameters of tooth extraction causes, such as iatrogenic, failure of RCT, trauma, and PA lesions, were recorded in the young age groups but their prevalence shows no significant difference. 


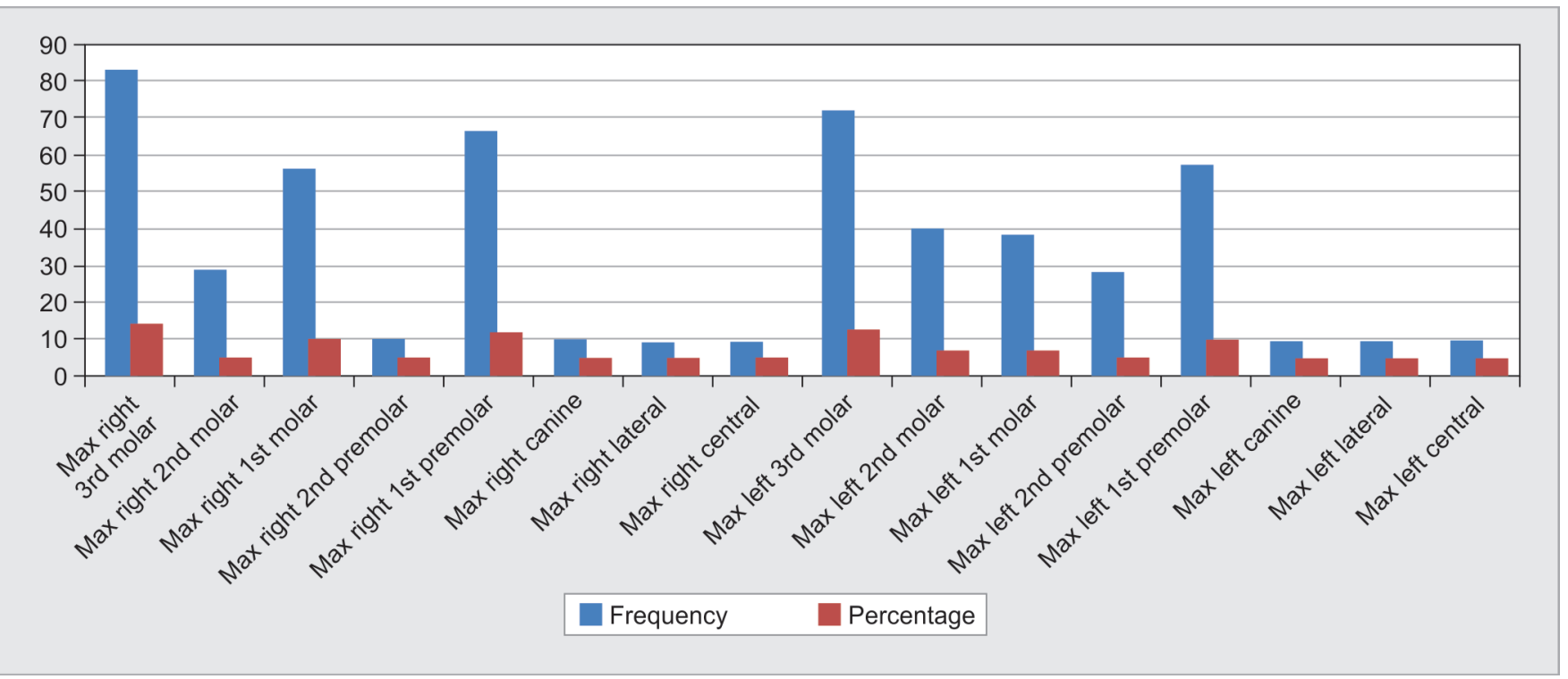

Graph 1: Maxillary descriptive of the site of tooth loss

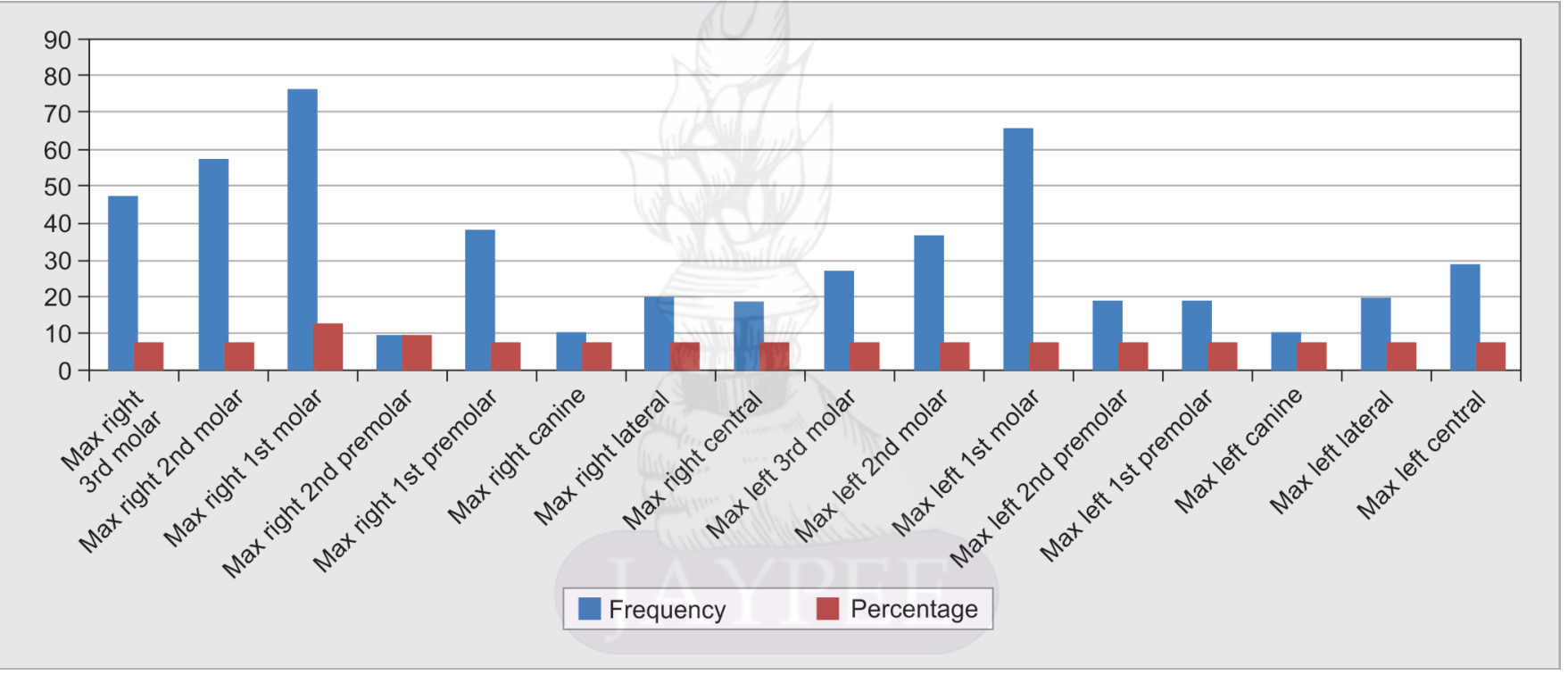

Graph 2: Mandibular descriptive of the site of tooth loss

mandibular arch right $77 ; 13.3 \%$ and left $66 ; 11.4 \%$. On the left side of both arches (the usual site of khat chewing), the highest was the third molar $(120 ; 20.7 \%$, followed by the first molar $115 ; 19.9 \%$. The maxillary first premolars, right $66 ; 11.4 \%$ and left $57 ; 9.8 \%$ were extracted more often than from the mandibular. Maxillary and mandibular anterior teeth and canines were the least extracted teeth and ranged from $9 ; 1.6 \%$ in maxillary teeth and $9-29 ; 1.6-5 \%$ in the mandibular teeth.

\section{Discussion}

Taiz city is the capital of Taiz Governorate, which is the most densely populated governorates of Yemen. It is inhabited by about $13 \%$ of the population of the country. It is located about $90 \mathrm{~km}$ from the port city of Mocha on the Red Sea and $256 \mathrm{~km}$ south of the capital of Yemen "Sana 'a". Tooth extraction is a common daily surgical procedure. Here we investigated the reasons for teeth loss and its relationships with age, gender, and location in the arch. Also, we aimed to recognize any associations between causes of tooth loss and several habits namely; khat chewing, Shammah using, smoking, teeth brushing and the use of Miswak.

A single study has investigated the prevalence of dental caries in Taiz and Yemen in general. ${ }^{36}$ We found that caries was the main cause of teeth loss in $43 \%$ and $65.4 \%$ of $15-24$ and $25-34$-year-olds (Table 2). These findings are in line with previous studies conducted in neighboring Jazan of Saudi Arabia Al Moaleem et al. ${ }^{16} 30.1 \%$ and other cities ${ }^{4,5}$ in SA Riyadh and Al-Madinah Al-Munawarah $50.2 \%$, and $63.4 \%$, respectively. Other studies reported similar results, with caries being responsible for most of the extractions, with proportions ranging from $39.2 \%$ to $85.3 \%$, Anand and Kuriakose, Nasreen and Haq, Jafarian and Etebarian, Anyanechi and Chukwuneke, Kashif et al., Haseeb et al., Yousaf et al., Lee et al., Montandon et al., Al-Shammari et al, Sayegh et al., Baqain et al., Chrysanthakopoulos, Sahibzada et al., Kaira et al. ${ }^{6-14,18-23}$ 
Social habits and risk factors that cause tooth loss in Taiz, Yemen

Periodontal disease is a persistent bacterial infection characterized by the progressive destruction of the toothsupporting structures and can lead to tooth loss. By triggering inflammatory reactions, periodontitis can detrimentally affect systemic health. ${ }^{37}$ In the current study, periodontal disease was low in the young age groups $4.1 \% ; 15-24$ years and $29.3 \%$; $25-34$ years and increased in the middle age groups $51.1 \%$; 35-44 years and $61.7 \% ; 45-54$ years and reach $100 \%$ at the age group of more than 55-64 years among the extracted subjects (Table 2). A similar finding was reported by a local study Ali et al. ${ }^{3}$ and in a study conducted in Al Moaleem et al. ${ }^{16}$ Other researchers' concluded that caries and periodontal disease are equally involved in as causes of tooth loss Chrysanthakopoulos and Aderinokun and Dosumu. ${ }^{21,25}$

In the current study, $26.6 \%$ of cases (Table 2), were registered that, orthodontic indications were the cause of tooth loss and it was totally among the young age group 15-24. In a study investigating orthodontic treatment needs among Yemenis patients, ${ }^{38}$ it was reported that only around $2 \%$ had orthodontic treatments due to limited finances. Others reported a high prevalence of premature loss of primary teeth $40.5 \%$, where the mandibular left primary second molar was the most commonly missed tooth in the dental arch. ${ }^{39}$ Several studies mentioned that orthodontic indications were the main responsible of the extractions in a range from $2 \%$ to $19.4 \%$ Ali et al., Alesia and Khali, Al Ameer et al., Anand and Kuriakose, Nasreen and Haq, Jafarian and Etebarian, Kashif et al, Yousaf et al., Gossadi et al., Al-Shammari et al., Sahibzada et al. and Kaira et al. ${ }^{3-8,10,12,15,18,22-23}$

The failure of RCT registered in the current study was between 4.9-7.4\%, which is slightly more than what was reported by Al Ameer et al., Kashif et al., Al-Shammari et al., Sahibzada et al. and Kaira et al., $5,10,18,22-23$ this could be explained by socioeconomic status which determines the materials and equipment used for RCT and quality of provided treatment. Regarding trauma, the registered percentage 3.7-4.9\% was more than the percentages mentioned in other studies Al Ameer et al. ${ }^{5} 0.2 \%$, Sayegh et al. ${ }^{19} 0.7 \%$, Baqain et al. ${ }^{20} 2.4 \%$, Sahibzada et al..$^{22} 1 \%$, and Kaira et al. ${ }^{23} 0.29 \%$, but it was equal to the percentage mentioned by Haseeb et al. ${ }^{11}$ and $\mathrm{Al}$ Moaleem ${ }^{25} 3.2 \%$, and $4.1 \%$, respectively, and less than a single study conducted in Jazan, Saudi Arabia, Al Moaleem et al. ${ }^{16}$ which was $12.1 \%$, this can be explained by the high number of the daily traffic accident in SA (Table 2).

Females accounted for $63.2 \%$ of the sample (Table 3). The females in the study had more dental caries than the males, but the males had a higher prevalence of PD 34.2\% than females. These findings agree with those of studies Alesia and Khali, Al Ameer et al., Nasreen and Haq, Jafarian and Etebarian, Kashif et al., ${ }^{4-5,7-8,10}$ but disagreed with the results reported in studiesHaseeb et al. and Yousaf et al. ${ }^{11,12}$ This absence of complete consensus could be due to the small sample sizes of these latter studies. Our findings agreed that female khat chewers had a significantly higher rate of tooth loss compared to non-khat chewers, especially in the 55-64-yearold group (Table 2 ).

The leaves of khat or the powder of Shammah are usually kept in the buccal vestibule of the mouth, or occasionally the lingual or lower labial vestibules for Shammah. ${ }^{27,28}$ Both habits have been put forward as risk factors for a negative effect on oral health, which might end with teeth mortality. Also, khat chewers had significantly more tooth loss than non-khat-chewers. ${ }^{28-30}$ Others have proposed consumption of Khat and Shammah as major reasons for tooth wear. ${ }^{40}$ As noted in previous studies $\mathrm{Al}$ Moaleem ${ }^{26}$ and Bayaty et al., ${ }^{27}$ many of the oral health problems of Yemen subjects have been associated with Khat and there is a widespread belief that periodontal disease is more severe in khat chewers than non-chewers, ultimately leading to tooth mortality (Table 4). Significant differences existed between khat chewers and non-khat chewers also between Shammah users and nonShammah user's $p<0.001$, supporting the existing concept that these habits are associated with tooth loss.

Miswake use is effective as an oral hygiene aid and has antibacterial activity against oral bacteria. Thus, Miswake can help to maintain proper dental hygiene. ${ }^{31,32}$ Only a small proportion of our subjects used Miswake 61; 10.5\% (Table 1)

About $367,63.3 \%$ were smokers, which might be a major factor in tooth loss due to periodontal disease. However, this appears to be a less important factor in tooth loss due to caries. ${ }^{32}$ No significant differences were registered among subjects that used toothbrushes, Miswake, and smoking; which might be due to the relatively small sample size (Table 4).

Regarding the position and type of the extracted teeth, from Graphs 1 and 2, it is clear that the maxillary third molars were the most frequently extracted teeth $13.4 \%$; this is in agreements with previous studies Chrysanthakopoulos NA, Alesia and Khalil, Jafarian and Etebarian, Sahibzada et al..$^{2,4,8,22}$ Both maxillary and mandibular first molar teeth were commonly extracted in the current study; this is in line with the findings of cited studies Ali et al., Nasreen and Haq, Anyanechi and Chukwuneke, Kashif et al., Al Moaleem et al., $3,7,9,10,16$ which could be explained by the early time of eruption of the first molar in the oral cavity. Our findings also agree with the studies of Alesia and Khali, Al Ameer et al., Lee et al., Montandon et al., Chrysanthakopoulos NA, 4,5,13,14,21 where anterior teeth were also frequently extracted mainly due to periodontal diseases, which results in the attachment loss with bone resorption around the root and eventually tooth mortality. This agrees with the previous conclusion concerning anterior teeth loss said by Al Ameer et al., Preethanathrs, Al-Shammari et al., Chrysanthakopoulos ${ }^{5,17,18,21}$ as shown in Graphs 1 and 2.

One of the limitations of the current study is that it is a crosssectional study. Also, the studies samples were collected from a warfree area, so that we did not cover the different demographic and socioeconomic zones. Also, in the khat chewing group, the period of chewing (hours per day, months, and years) was not registered, nor was the use of sugars and soft drinks, which are usually consumed during khat chewing and might affect the total results outcome of this parameter. In addition to the above-mentioned limitations, patients with the systemic disease should be considered since those types of patients might develop poor oral hygiene with increasing severity; this might lead to a greater risk of compromised tooth loss and oral hygiene. ${ }^{41}$

This study will facilitate and guide the development of treatment, as well as the preventive procedures relevant to the causes of teeth loss observed in this part of Yemen, thereby minimizing tooth loss and its adverse effects.

\section{Conclusion}

Within the scope of the current cross-sectional study, the following conclusions can be drawn; the main cause of tooth loss among subjects in Taiz, Yemen was dental caries and in the younger age group 15-24 and 25-34. Periodontal disease was the major cause among subjects $>45$-years-old. Most of the participants were in the 15-24 and 25-34-years-old groups. Females had undergone slightly more extractions than males. Molar teeth in both arches were the most frequently extracted, 
while most of the extractions of maxillary first premolars were for orthodontic treatment.

There are strong associations between tooth loss and khat chewing and Shammah use. Risk factors (using toothbrushes, Meswake, and smoking) altered the incidence of tooth extraction but statistical significance was lacking for tooth brushing and smoking. Further clinical trials and longitudinal studies should be conducted to confirm the findings reported here.

\section{Acknowledgment}

Authors want to thank Ms. Ahmed for her great support during collection of the questioner at Al Saeed University, Taiz, Yemen.

\section{References}

1. Aida J, Ando Y, Akhter R, et al. Reasons for permanent tooth extractions in Japan. J Epidemiol 2006;16: 214-219.

2. Chrysanthakopoulos NA. Reasons for extraction of permanent teeth in Greece: a five year follow-up study. Int Dent J 2011;61:19-24.

3. Ali HT, Saleh HO, Noman AF, et al. Periodontal indications for tooth extraction in the main general teaching hospital, Aden, Yemen: A prospective study. SRM J Res Dent Sci 2018;9:1-5.

4. Alesia K, Khalil H. Reasons for and patterns relating to the extraction of permanent teeth in a subset of the Saudi population. Clin, Cosmelnvestig Dent 2013;5:51-56.

5. Al Ameer HM, Awad S. Reasons for Permanent Teeth Extraction in Al-Madinah Al- Munawarah. JAMMR 2017;24(7):1-6.

6. Anand PS, Kuriakose S. Causes and Patterns of Loss of Permanent Teeth among Patients Attending a Dental Teaching Institution in South India. J Contemp Dent Pract 2009;10 (5):1-11.

7. Nasreen T, Haq ME. Factors of tooth extraction among adult patients attending in exodontia department of Dhaka Dental College and Hospital. Ban J Orthod Dentofac Orthop 2011;2:7-10.

8. Jafarian M, Etebarian A. Reasons for Extraction of Permanent Teeth in General Dental Practices in Tehran, Iran. Med Princ Pract 2013;22: 239-244.

9. Anyanechi C,Chukwuneke F. Survey of the Reasons for Dental Extraction in Eastern Nigeria. Ann Med Health Sci Res 2012;2(2):129-133.

10. Kashif M, Mehmood K, Ayub T, et al. Reasons and Patterns of Tooth Extraction in a Tertiary Care Hospital- A Cross Sectional Prospective Survey. J Liaquat Uni Med Health Sci 2014;13(03):125-129.

11. Haseeb M, Ali K, Munir MF. Causes of tooth extraction at a tertiary care centre in Pakistan. J Pak Med Assoc 2012; 62(8); 812-815.

12. Yousaf $A$, Mahmood S, Yousaf N, et al. Reasons For Extractions in Patients Seen in Pak Field Hospital Level 3 Darfur, Sudan. Paki Oral Dent J 2012;32(3):393-398.

13. Lee C-Y, Chang Y-Y, Shieh T-Y. Reasons for Permanent Tooth Extractions in Taiwan. Asia-Pacific J Public Health 2015;27(2): NP2352.

14. Montandon AB, Zuza EP, Corrde Toledo BE. Prevalence and Reasons for Tooth Loss in a Sample from a Dental Clinic in Brazil. Inte J Den 2012; Article ID 719750, 5 pages.

15. Gossadi YI, Al Moaleem MM et al. Reasons for Permanent Teeth Extraction in Jizan Region of Saudi Arabia. IOSR-JDMS 2015;14:86-89.

16. Al Moaleem MM, Somaili DA, Ageeli TA, et al. Pattern of partial edentulism and its relation to age, gender, causes of teeth loss in Jazan population. Ame J Heal Rese 2016;4:121-126.

17. Preethanath RS. Reasons For Tooth Extraction In Urban And Rural Populations Of Saudi Arabia. Paki Oral Dent J 2010;30:199-204.

18. Al-Shammari KF, Al-Ansari JM, Abu Al-Melh M, et al. Reasons for Tooth Extraction in Kuwait. Med Princ Pract 2006;15: 417-422.
19. Sayegh A, Hilow $H$, Bedi R. Pattern of tooth loss in recipients of free dental treatment at the University Hospital of Amman, Jordan. J Oral Rehabil 2004; 31(2):124-130.

20. Baqain ZH, Khraisat A, Sawair F, et al. Dental extraction for patients presenting at oral surgery student clinic. CompendContinEduc Dent 2007; 28(3):146-150.

21. Chrysanthakopoulos NA. Periodontal Reasons for Tooth Extraction in a Group of Greek Army Personnel. JOD 2011;5:56-60.

22. Sahibzada HA, MunirA, Siddiqi KM, et al. Pattern and Causes of Tooth Extraction in Patients Reporting to a Teaching Dental Hospital. JIMDC 2016:5(4):172-176.

23. Kaira LS, Dabral E, Sharma R, et al. Reasons for Permanent Teeth Extraction in Srinagar District of Uttrakhand. OHDM 2016; 15(4): 247-251.

24. Murray H, Locker D, Kay EJ. Patterns of and reasons for tooth extractions in general dental practice in Ontario, Canada. Community Dent Oral Epidemiol 1996;24:196-200.

25. Aderinokun GA, Dosumu OO. Causes of tooth mortality in a Nigerian Urban Centre. Odontostomatol Trop 1997;79:68.

26. Al Moaleem MM. Patterns of Partial Edentulism and its Relation to Khat Chewing in Jazan Population - A Survey Study. J Clini Diag Rese 2017;11(3):ZC55-ZC59.

27. Bayaty FH, Wahid Ali NA, Bulgiba AM, et al. Tooth mortality in khat and non khat chewer in Sana'a Yemen. Scie Rese Essays 2011;6:1039-1045.

28. Astatkie A, Demissie M, Berhane $Y$, et al. Oral symptoms significantly higher among long-term khat (Catha edulis) users in Ethiopia. Epidemiology and Health 2015;37:6.

29. Al-Maweri SA, Al-Sufyani GOP. Prevalence of oral cancer, potentially malignant lesions and oral habits among patients visiting dental school, Sana'a University. Oral Oncol 2013;49:S59-62.

30. Alsanosy RM. Smokeless tobacco (Shammah) in Saudi Arabia: a review of its pattern of use, prevalence, and potential role in oral cancer. Asian Pac J Cancer Prev 2014;15(16):6477-6483.

31. Halawany HS. A review on meswak (Salvadorapersica) and its effect on various aspects of oral health. Saudi Dent J 2012;24:63-69.

32. Ahmad H, Rajagopal K. Salvadorapersica L. Meswak in dental hygiene. Saudi J Dent Rese 2014;5:130-134.

33. Mai X, wactawski-weade, Hovey KM et al. Associations between smoking and tooth loss according to reason for tooth loss. J Am Dent Assoc 2013;144(3):252-265.

34. Cahen PM, Frank RM, Turlot C. A survey of the reasons for dental extractions in France. J Dent Rese 1985;64(8):1087-1093.

35. Ainamo J, Sarkki L, Kuhalampi Ml, et al. The frequency of periodontal extractions in Finland. Comm Dent Heath 1985;1:165-172.

36. Al- Haddad K A-S. Assessment of Oral Health Status and Treatment Needs of 5-Year-Old and 12-Year-Old children in Yemen. PhD Thesis, University of Khartoum, 2006.

37. Elhassan AT, Alfakry H, Peeran SW. Reasons to seek periodontal treatment in a Libyan community. Dent Med Res 2017;5:38-42.

38. Al-Zubair NM. Perception of occlusion and reasons for not seeking orthodontic treatment among Yemeni children.J Orthod Res 2014;2:68-73

39. Murshid SA, Al-Labani MA, Aldhorae KA, et al. Prevalence of prematurely lost primary teeth in 5-10-year-old children in Thamar city, Yemen: A cross-sectional study. J Int Soc Prev Community Dent 2016;6(Suppl 2):S126-S130.

40. Sayed ME, Hamdi AD, Hakami BM, et al. Tooth Wear Patterns among Khat and Shammah Users in Jazan City, Kingdom of Saudi Arabia: A Cross-sectional Survey. J Contemp Dent Pract 2017; 18(6):429-436.

41. Haq MH, Tanwir F, Nawaz M, Tabassum S, Jabar M. Association of Systemic Diseases on Tooth Loss and Oral Health. J Biomedical Sci 2016;4:1-7. 